\section{Cureus}

Received 08/19/2017

Review began 08/29/2017

Review ended 09/08/2017

Published 09/11/2017

\section{(c) Copyright 2017}

Moreno-Caviedes et al. This is an open access article distributed under the terms of the Creative Commons Attribution License CC-BY 3.0., which permits unrestricted use, distribution, and reproduction in any medium, provided the original author and source are credited.

\title{
Characterization of Eyeball Loss in Four Cities of Colombia
}

\author{
F. Hernán Moreno-Caviedes ${ }^{1}$, Nórida Velez Cuellar ${ }^{2}$, Margarita Caicedo Zapata ${ }^{3}$, Gabriel \\ Triana Reina ${ }^{3}$, Azucena Sánchez ${ }^{3}$ \\ 1. School of Optometry, Fundación Universitaria Del Área Andina (colombia), Pereira, COL 2. \\ Epidemiology, Universidad El Bosque (colombia) 3. Universidad De La Salle (colombia), Fellow Asoprot
}

$\square$ Corresponding author: F. Hernán Moreno-Caviedes, info@bioprot.com.co Disclosures can be found in Additional Information at the end of the article

\section{Abstract}

Purpose: Describe the socio-demographic characteristics of anophthalmic patients examined at specialized centers of four cities in Colombia to know the different causes of eyeball loss.

Method: A transversal retrospective study was done of 511 medical records from the specialized practices of four cities in Colombia. Socio-demographic data of patients who were seen between January 2011 and December 2013 were compiled. SOFA Statistics software v1.4.6 was used for this analysis. An analysis throughout the measures of central tendency for numerical variables was developed, and the descriptive statistics were used for the categorical variables.

Results: Almost 63\% of the data belonged to male patients. Eyeball loss was more frequent in patients over 40 years of age. Fifty-one percent of the patients suffered eyeball loss due to traumatic causes, $40.2 \%$ due to pathological causes, and $4.6 \%$ due to congenital anomalies. The most frequent specific causes were glaucoma (19\%), ocular cancer (15.4\%), and home accidents $(11,2 \%)$. Around $60 \%$ of the anophthalmic patients belonged to low socioeconomic level.

Conclusions: It is important to highlight that more than half of the analyzed anophthalmia cases originated in some type of trauma; this means that they could be considered potentially avoidable losses. Complications deriving from glaucoma became the most frequent cause of anophthalmia in the pathological origin group, which suggests a reflection regarding the strategies of early detection of the disease and access to proper treatment. It is also showed the need to develop an efficient system to manage information.

Categories: Miscellaneous

Keywords: anophthalmos, eye injuries, eye evisceration, ocular prosthesis

\section{Introduction}

Anophthalmia or the absence of ocular structures inside the ocular socket may be of congenital origin, it can occur in an isolated way or as part of a chromosomal syndrome, and it may occur in an acquired form because of multiple situations [1].

The prevalence of births with anophthalmia in the general population has been estimated in 3 X 106 inhabitants, commonly with a bilateral presentation of the disease [2-3]. Alternately, a study in 212,479 consecutive live births found a prevalence rate of anophthalmia of $0.23 \%$ per 10,000 live births [4]. Some of the risk factors described for this condition include hereditary factors, environmental factors, maternal and gestational variables (multiple births, low weight 
at birth, and drug use), the own characteristics of the patient (over 40 years of age), and genetic alterations (chromosomal abnormalities, duplication syndrome, Wolf Hirschhorn syndrome, and triploidy), among others $[1,5]$.

Researchers analyzed the records of around 5.7 million births and reported rates of microphthalmia and anophthalmia at a rate of 0.92 to 2.29 per 100,000 births in France, Sweden, and the United states [6]. In 2006, Forrester MB et al. determined a ratio of 3.21 per 100,000 births for microphthalmia and anophthalmia in a total of 298,994 registered births between 1986 and 2001 in Hawaii [7].

A report published in Colombia by the National Institute of Health showed that the ocular anomalies represented 2.51\% of all genetic congenital alterations for 2013 [8]. In 2016, 7,153 cases of congenital defects were reported by SIVIGILA (public health monitoring system) of which 82 cases (1.1\%) were related to sensorial defects [9]; however, such reports do not have information about specific ocular anomalies. According to data from the National Administrative Department of Statistics (DANE), in Colombia, there is a total of 348,620 people (17.2\%) with a disability related to the eyes [10], but the type of disease suffered by the patient is not discriminated.

There is a lack of information about the different circumstances that cause the loss of the visual organ and the characteristics of the patients that suffer this disease. Besides, there is no clear data about the rate of congenital anophthalmia in the Colombian population. The purpose of this paper is to describe the socio-demographic characteristics of anophthalmic patients evaluated in specialized centers of four cities of Colombia to know the different causes of eyeball loss and to promote interest in studying this special condition.

\section{Materials And Methods}

\section{Study design}

Retrospective transversal study

\section{Data collection}

Anophthalmia medical records were collected from specialized eye rehabilitation practices that had a certified professional in four cities of Colombia (Barranquilla, Cali, Ibagué, and Pereira). Data were reviewed between January 2011 and December 2013. Records with other types of ocular alterations, such as microphthalmia, macrophthalmia, or corneal leukoma, were excluded.

\section{Analysis of results}

For the numerical variables, an analysis throughout the measures of central tendency was developed and descriptive statistics were used for the categorical variables. SOFA Statistics software V1.4.6 was used for data analysis (www.sofastatistics.com). Recommendations made in the Strengthening the Reporting of Observational studies in Epidemiology (STROBE) initiative were considered [11].

\section{Results}

A total number of 629 cases of patients with the diagnosis of anophthalmia were analyzed in four cities: Barranquilla, Cali, Ibagué, and Pereira (Figure 1); 118 cases were excluded because they did not meet the inclusion criteria. 


\section{Cureus}

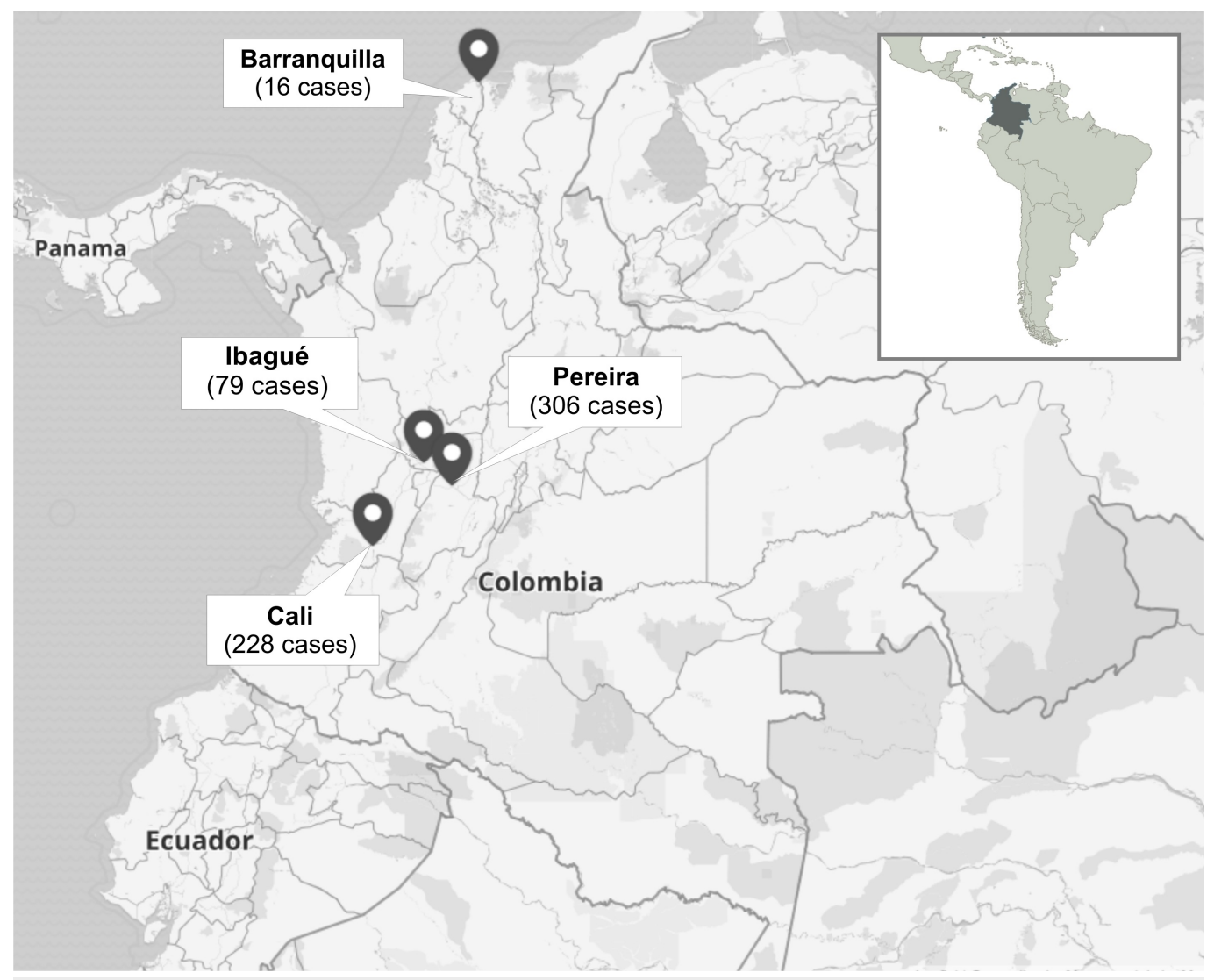

FIGURE 1: Distribution of cases of anophthalmia in four cities of Colombia

Around 63\% (n=321) of the cases belonged to male patients, with an age range of six months to 90 years and an average age of 43.4 years for 455 cases that registered the patient's age. Approximately $52 \%$ of cases were above 40 years' old and around the fourth part of the data belonged to patients over 60 years' old, which indicates a greater occurrence of anophthalmia as age increases, for the analyzed records (Table 1). Bilateral anophthalmia was described in 14 cases and the unilateral disease was presented without big differences between the right and left eyes.

n 321 190 511
$\%$

62.8

37.2

100

16-25

26-39 


\section{Cureus}

40-59

60-90

Affected eye

Right eye

Socioeconomic status

Low

Medium

High

Job type

Student

Retired

TABLE 1: Demographic characteristics, affected eye, economic level, job type, and causes of anophthalmia in four cities of Colombia

The socioeconomic situation was known in 240 cases; $61.3 \%$ of the records belonged to patients of low socioeconomic level. Eyeball losses related to trauma were more frequent in men of low economic level.

Forty-nine different types of jobs were identified in 257 cases that had such information; these were grouped into five categories where only $10 \%(n=51)$ of the cases reported to have formal employment. Regarding specific jobs, $10.8 \%$ of the cases were represented by housewives, followed by patients who said they were retired (6.7\%), and others who worked in activities related to agriculture (4.3\%). The cases of patients who were in elementary school or high 


\section{Cureus}

school represented 6.1\%. Other jobs included business people, drivers, administrative staff, technical staff, and mechanics, among others (Table 2).

\begin{tabular}{|c|c|c|}
\hline Occupation & $\mathbf{n}$ & $\%$ \\
\hline No data & 229 & 44.8 \\
\hline Housewife & 55 & 10.8 \\
\hline Others & 54 & 10.6 \\
\hline Retired & 34 & 6.7 \\
\hline Children under four years & 25 & 4.9 \\
\hline Agriculture & 22 & 4.3 \\
\hline Cleaning service & 16 & 3.1 \\
\hline Primary school & 16 & 3.1 \\
\hline High school student & 15 & 2.9 \\
\hline Self-employed & 13 & 2.5 \\
\hline Construction & 11 & 2.2 \\
\hline College student & 9 & 1.8 \\
\hline Salesman & 6 & 1.2 \\
\hline Teacher & 6 & 1.2 \\
\hline Total & 511 & 100 \\
\hline
\end{tabular}

\section{TABLE 2: Frequency of anophthalmia according to specific occupation}

The causes of the eye globe loss were grouped into four categories or etiological groups: traumatic, congenital, pathological, and unknown causes. Approximately $51 \%(n=260)$ of anophthalmia cases derived from some type of trauma. Eyeball loss related to common violence and home or traffic accidents were in a proportion of 4:1 for the male group versus the female group; patients between 40 and 59 years' old presented a higher frequency of eye loss related to accidents and violence compared with the other groups. For the female group, eyeball loss due to pathological causes was the most common (Figure 2). 


\section{Cureus}

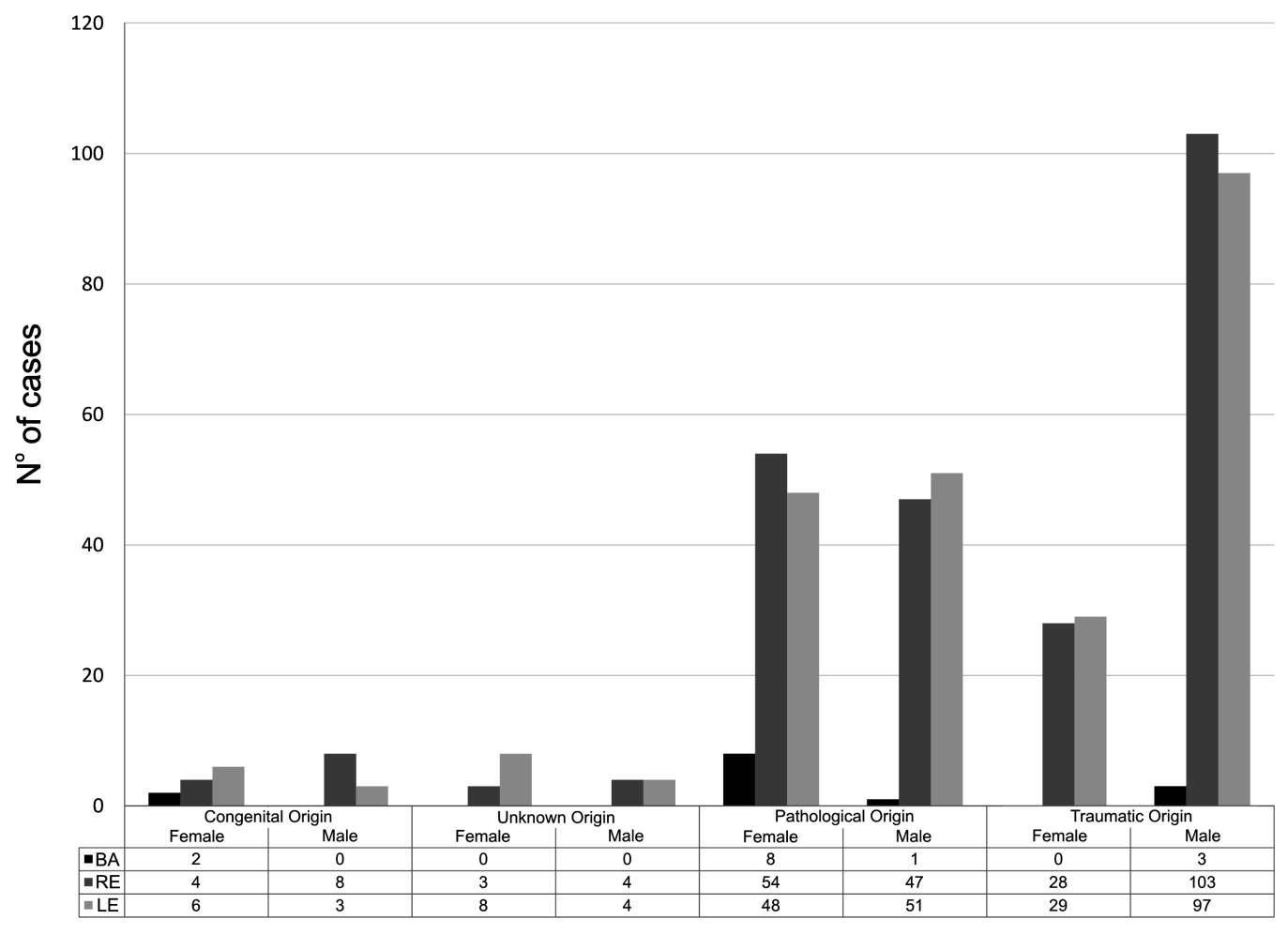

BA= Both Eyes $\mathbf{R E}=$ Right Eye LE= Left Eye

FIGURE 2: Description of the eyeball loss according to the type of cause, genre, and affected eye

In the pathological causes group, the most frequent cause was glaucoma, followed by ocular cancer and intraocular infections. In patients over 60 years' old, glaucoma was more frequent as well as secondary complications of ocular surgery, where cataract extraction with intraocular lens implant was the most common surgery. There was no information about the specific type of glaucoma. Retinoblastoma was the most common (73.7\%) in the group with ocular cancer, in which patients under 15 years of age represented $55.9 \%$ of the cases. In addition, 23 cases of congenital anophthalmia were found (Figure 3). 


\section{Cureus}

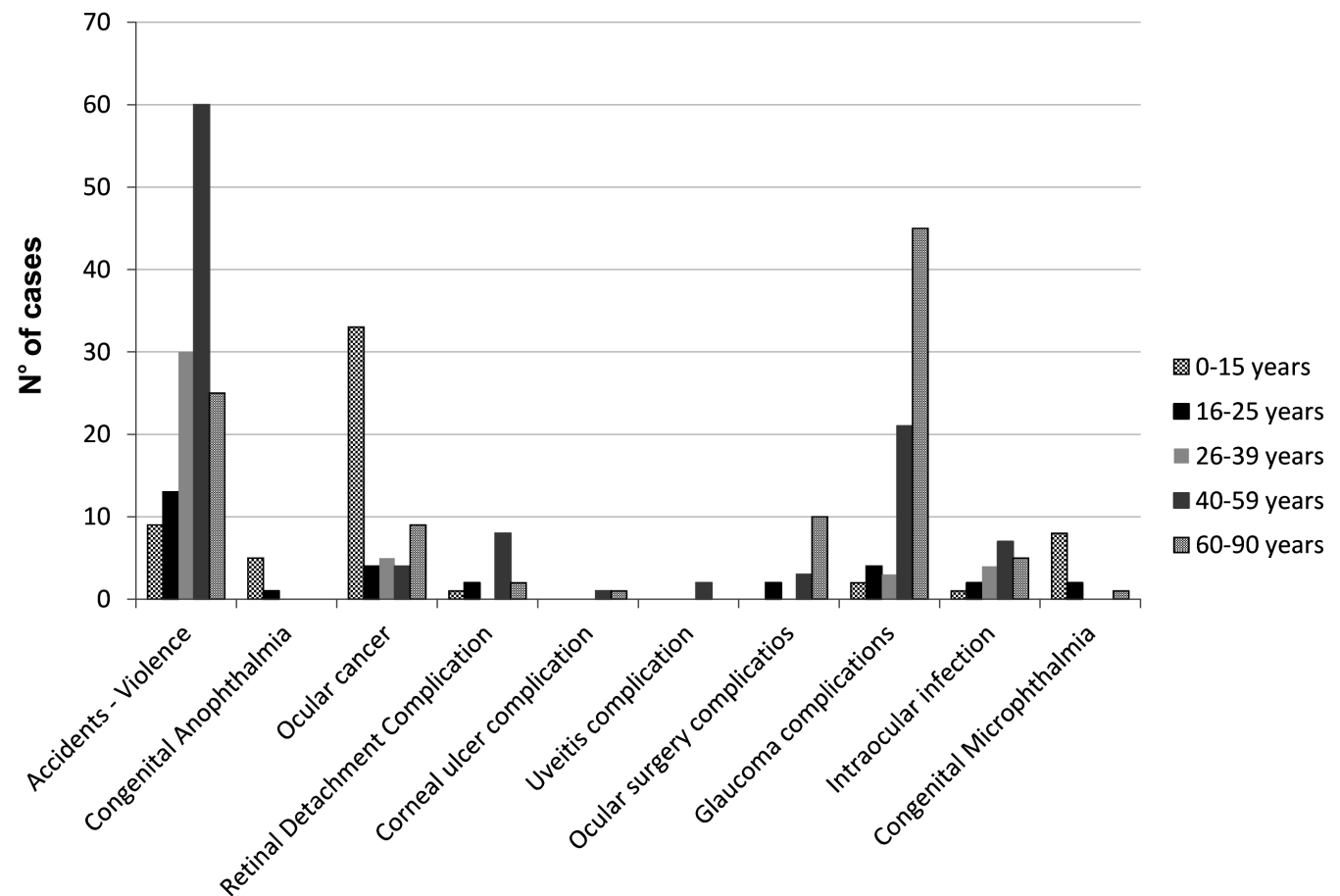

Specific cause of eye globe loss

FIGURE 3: Distribution of eye globe loss according to specific cause and age

Information about the use of an ocular prosthesis was obtained in 311 medical records; 30.5\% $(n=95)$ were already users of an ocular prosthesis by the time they were examined. Only 73 cases registered the time of use of an ocular prosthesis with an average time of 21.1 years and a maximum time of 55 years. Over $75 \%$ of the patients reported having used the same ocular prosthesis for more than 10 years.

In $85.9 \%$ of the cases, the type of surgery was known; evisceration was the most frequent (51.3\%). Two cases of exenteration or the removal of the orbital contents and ocular adnexa were found.

There was neither information about the enucleations that were performed with or without an ocular implant, nor information about the types or characteristics of the implants used. Other procedures registered were enucleation (33.3\%), dermal-fat graft (0.59\%), and fornix reconstruction (0.39\%). The medical records reviewed did not have relevant information about post-surgical follow-up or post-surgical complications.

\section{Discussion}

There are a few studies about anophthalmia and eyeball loss in Colombia; however, this is the first paper that explores the characteristics of this anomaly in different cities of the country. The unilateral affection was presented without significant differences between the right and left eyes; the frequency for both was close to $50 \%$. These results were similar to others authors in Brazil and the United States [7,12].

In 2013, Sousa RL et al. analyzed medical records in the western central area of Sao Paulo, and he observed that this anomaly affects a higher proportion of men over 40 years of age. Among 
the causes of anophthalmia, he found pathologies such as glaucoma (painful blind eye). His findings were consistent with the results of this paper, where complications related to glaucoma were $37.7 \%$ in the group of pathologies that caused eye loss. There are also consistencies regarding the age groups and the pathologies related to the eye globe loss. A greater occurrence of anophthalmia was related to traumatic incidents (work-related accidents, traffic accidents, and common violence) in male individuals, similar to that reported by other studies [13].

Incidents related to home accidents, common violence, traffic accidents, and work accidents made a total of $42.7 \%$ of the records analyzed, which indicates that about half of the anophthalmia cases could potentially be avoidable, just as is stated in other investigations [14$15]$.

In 2014, the Ministry of Health presented a report about the socio-economical determining factors of the violence in Colombia, and although it did not mention the frequency of victims with ocular damage, it did describe the distribution of different types of violence according to gender and geographical area [16]. The eye globe loss because of violence represented an important number in this investigation (17.3\%); common violence events were the most frequent compared to domestic violence and armed conflict, having a higher occurrence among those who were between 26 and 59 years of age and with a proportion of 4:1 for the male genre, which is consistent with Ramos Souza et al., who found, in 2012, the highest rates of violence in populations between 15 and 49 years of age and with a higher frequency in the male gender [17].

More than half of the patients with the anophthalmia diagnosis were over 40 years of age, which might suggest that the possibility of suffering a condition that may lead to eyeball loss increases with age. Complications derived from glaucoma constituted the most frequent cause of loss of the organ of vision in the pathological origin group. This result is high with respect to other papers checked [18], which implies a reflection with respect to the strategies for the early detection of the disease in Colombia, the possibilities of access to proper treatment, and the treatment schemes currently used for the control of the disease.

The time for the replacement of the ocular prosthesis was extremely long since the average time of use of the same ocular prosthesis was more than 20 years, making evident the absence of a control and follow-up scheme for patients that have suffered the loss of one eye, considering that the use of a damaged ocular prosthesis might cause complications and chronic discomfort in the anophthalmic patient. This is similar to how it is described in studies done by specialists at the Cuban Institute of Ophthalmology in 2010 and 2014, where it was found that conjunctival fornix retraction, infectious processes, and allergic reactions are the most frequent conditions in patients who wear an ocular prosthesis [19-20]. This special type of patient requires professional support for the adequate care and maintenance of the artificial eye. Furthermore, a periodical replacement of the ocular prosthesis is necessary to avoid injuries and damage to the ocular socket tissue.

More than $60 \%$ of the cases analyzed belonged to the low economic levels; however, Colombia's health system does not cover the treatment expenses related to the ocular prosthesis. Perhaps it is necessary to review the current health policies to promote a truly comprehensive access to health services.

One of the limitations of this paper was the quality of the information available in many of the medical records checked since, in some cases, relevant data, such as the cause of the loss, education level, occupation, economic level, type of cause, and patient's age was not found. It is necessary to develop an adequate system for the management and collection of information. 
It is convenient to develop analytical studies that allow us to determine associations among the occurrence of anophthalmia and demographic, and clinical and etiological variables.

\section{Conclusions}

There is a lack of information about the different circumstances that cause the loss of the eyeball and the characteristics of anophthalmic patients. Furthermore, there is no clear data about the rate of congenital anophthalmia in the Colombian population. In this study, over $40 \%$ of the records corresponded to patients in the productive age (between 26 and 60 years). The male genre was the most affected (63\%), and ocular trauma was the main cause of eye loss. Eye losses related to trauma were more frequent in men of low economic level.

Glaucoma complications were the main pathological cause (37.7\%) and retinoblastoma was the most frequent neoplasm in patients under 15 years of age. Most of the eye losses (68.3\%) were related to potentially preventable events. Bilateral anophthalmia was found in $2.7 \%$ of the cases, and the unilateral compromise was similar for the right and left eyes.

Over $75 \%$ of the patients reported having used the same ocular prosthesis for more than 10 years, which indicates that in Colombia, there does not exist an adequate scheme for specialized control and follow-up to ocular prosthesis wearers. Moreover, $63 \%$ of records containing data about income belonged to the low economic strata. This is the first research that describes the causes of eyeball loss in different Colombian cities.

\section{Additional Information}

\section{Disclosures}

Human subjects: Consent was obtained by all participants in this study. Animal subjects: All authors have confirmed that this study did not involve animal subjects or tissue. Conflicts of interest: In compliance with the ICMJE uniform disclosure form, all authors declare the following: Payment/services info: All authors have declared that no financial support was received from any organization for the submitted work. Financial relationships: All authors have declared that they have no financial relationships at present or within the previous three years with any organizations that might have an interest in the submitted work. Other relationships: All authors have declared that there are no other relationships or activities that could appear to have influenced the submitted work.

\section{Acknowledgements}

To the health professionals who provided access to medical records for developing this paper

\section{References}

1. Verma AS, Fitzpatrick DR: Anophthalmia and microphthalmia. Orphanet J Rare Dis. 2007, 2:47. 10.1186/1750-1172-2-47

2. Morrison D, Fitzpatrick D, Hanson I, et al.: National study of microphthalmia, anophthalmia, and coloboma (MAC) in Scotland: investigation of genetic etiology. J Med Genet. 2002, 39:1622. 10.1136/jmg.39.1.16

3. Mazzoli R, Raymond W, Ainbinder D, Hansen E: Use of self-expanding, hydrophilic osmotic expanders (hydrogel) in the reconstruction of congenital clinical anophthalmos. Curr Opin Ophthalmol. 2004, 15:426-431. 10.1097/01.icu.0000138618.61059.4c

4. Aijaz S, Clark BJ, Williamson K, et al.: Absence of SIX6 mutations in microphthalmia, anophthalmia and coloboma. Invest. Ophthalmol Vis Sci. 2004, 45:3871-3876.

doi:10.1167/iovs.04-0641

5. Shaw G, Carmichael S, Yang W, Harris J, Finnell R, Lammer E: Epidemiologic characteristics 
of anophthalmia and bilateral microphthalmia among 2.5 million births in California, 19891997. Am J Med Genet A. 2005, 137A:36-40. 10.1002/ajmg.a.30840

6. Kallen B, Robert E, Harris J: The descriptive epidemiology of anophthalmia and microphthalmia. Int J Epidemiol. 1996, 25:1009-1016. 10.1093/ije/25.5.1009

7. Forrester M, Merz R: Descriptive epidemiology of anophthalmia and microphthalmia, Hawaii, 1986-2001. Birth Defects Res A Clin Mol Teratol. 2006, 76:187-192. 10.1002/bdra.20237

8. Instituto Nacional de Salud. Final report of congenital anomalies (2013) [Spanish] . Instituto Nacional de Salud. 2014, Accessed: Agosto 18 de 2017: http://www.ins.gov.co/lineas-deaccion/SubdireccionVigilancia/Informe\%20de\%20Evento\%20Epidemiolgico/ANOMALIAS\%20CONG....

9. Instituto Nacional de Salud. Surveillance report of birth defects: XIII epidemiological period (2016) [Spanish]. Instituto Nacional de Salud. 2016, Accessed: August 18, 2017 : http://www.ins.gov.co/lineas-de-accion/SubdireccionVigilancia/Informe\%20de\%20Evento\%20Epidemiolgico/DEFECTOS\%20CONGE....

10. DANE: Identification of persons with disabilities in Colombia: national total [Spanish] . 2016, Accessed: Octubre 10 de 2016: http://www.dane.gov.co/files/investigaciones/discapacidad/Total_nacional.xls.

11. Vandenbroucke JP, Von Elm E, Altman DG, et al.: Strengthening the reporting of observational studies in epidemiology (STROBE): explanation and elaboration [Spanish]. Gac Sanit. 2009, 23:158.e1-158.e28. 10.1016/j.gaceta.2008.12.001

12. Sousa RL, Marçon AR, Padovani CR, Schellini SA: Frequency of occurrence of anophthalmic socket in the Middle West region of the state of São Paulo and the carriers characteristics [Portuguese]. Arq Bras Oftalmol. 2013, 2:90-93. 10.1590/S0004-27492013000200007

13. Modugno A, Mantelli F, Sposato S, Moretti C, Lambiase A, Bonini S: Ocular prostheses in the last century: a retrospective analysis of 8018 patients. Eye (Lond). 2013, 27:865-870. 10.1038/eye.2013.97

14. Burgeño C, Colunga M, Gonzalez E, Cienfuegos S, Díez-Lague A, Diab M: Ocular Trauma in childhood [Spanish]. An Esp Pediatr. 1998, 48:625-630. Accessed: Octubre 15 de 2016: http://www.aeped.es/sites/default/files/anales/48-6-11.pdf.

15. Rodríguez DJ, Rey DJ, González MC, Varela G: Perforating ocular trauma in children [Spanish] . Archivo Médico de Camagüey. 2005, 9:97-105. Accessed: Octubre 15 de 2016: http://www.redalyc.org/articulo.oa?id=211117924010.

16. Ministerio de Salud y Protección Social. Socio-economic determinants of the gender-based violence in Colombia (2010-2013) [Spanish]. 2014, 1-76. Accessed: Noviembre 18 de 2016:

17. De Sousa E, De Melo A, Silva J, Franco S, Alazraqui M, González-Pérez G: Multicentric study of deaths by homicide in Latin American countries [Portuguese]. Cien Saude Colet. 2012, 17:3183-3193. 10.1590/S1413-81232012001200004

18. Narikawa S, Natsuaki K, Fruet J, Padovani C, Schellini S: Profile of patients with anophthalmic cavity: study at Faculdade de Medicina de Botucatu - UNESP [Portuguese]. Arq Bras Oftalmol. 2011, 74:357-360. 10.1590/S0004-27492011000500010

19. Ramírez L, Gómez C, Díaz M: Atypical anophthalmic cavities [Spanish]. Rev Cubana Oftalmol. 2010, 23:49-56. Accessed: Julio 10 de 2017: http://scieloprueba.sld.cu/scielo.php? script=sci_arttext \&pid=S0864-21762010000100005\&lng=es.

20. Ramírez L, Martínez A, Gómez C, Díaz M, Rojas I, Carrazana Y: Conjunctival diseases of patients with ocular prosthesis [Spanish]. Rev Cubana Oftalmol. 2014, 24:390-402. Accessed: Febrero 12 de 2017: http://www.revoftalmologia.sld.cu/index.php/oftalmologia/article/view/323/html_114. 